\title{
Lumbar microdiscectomy for sciatica in adolescents: a multicentre observational registry-based study
}

\author{
Sasha Gulati ${ }^{1,2,3}$ - Mattis A. Madsbu ${ }^{1}$ - Tore K. Solberg ${ }^{4,5}$ - Andreas Sørlie, . $^{4,5}$ \\ Charalampis Giannadakis $^{2,6}$ • Marius K. Skram ${ }^{7}$ - Øystein P. Nygaard ${ }^{1,2,3,5}$. \\ Asgeir S. Jakola ${ }^{1,8,9}$
}

Received: 22 November 2016/Accepted: 4 January 2017 /Published online: 16 January 2017

(C) The Author(s) 2017. This article is published with open access at Springerlink.com

\begin{abstract}
Background Lumbar disc herniation (LDH) is rare in the adolescent population. Factors predisposing to LDH in adolescents differ from adults with more cases being related to trauma or structural malformations. Further, there are limited data on patient-reported outcomes after lumbar microdiscectomy in adolescents. Our aim was to compare clinical outcomes at 1 year following single-level lumbar microdiscectomy in adolescents (13-19 years old) compared to younger adults (2050 years old) with $\mathrm{LDH}$.

Methods Data were collected through the Norwegian Registry for Spine Surgery. Patients were eligible if they had
\end{abstract}

Asgeir S. Jakola

legepost@gmail.com

1 Department of Neurosurgery, St. Olavs University Hospital, Trondheim, Norway

2 Department of Neuroscience, Norwegian University of Science and Technology (NTNU), Trondheim, Norway

3 National Advisory Unit on Spinal Surgery, St. Olavs University Hospital, Trondheim, Norway

4 Department of Neurosurgery, University Hospital of Northern Norway (UNN), Tromsø, Norway

5 The Norwegian National Registry for Spine Surgery, University Hospital of Northern Norway (UNN), Tromsø, Norway

6 Department of Medicine, Ålesund Hospital, Ålesund, Norway

7 Department of Paediatrics, Rikshospitalet, Oslo University Hospital, Oslo, Norway

8 Department of Neurosurgery, Sahlgrenska University Hospital, Blå Stråket 5, vån 3, 41345 Göteborg, Sweden

9 Institute of Neuroscience and Physiology, Sahlgrenska Academy, Gothenburg, Sweden radiculopathy due to $\mathrm{LDH}$, underwent single-level lumbar microdiscectomy between January 2007 and May 2014, and were between 13 and 50 years old at time of surgery. The primary endpoint was change in Oswestry Disability Index (ODI) 1 year after surgery. Secondary endpoints were generic quality of life (EuroQol five dimensions [EQ-5D]), back pain numerical rating scale (NRS), leg pain NRS and complications.

Results A total of 3,245 patients were included (97 patients 13-19 years old and 3,148 patients $20-50$ years old). A significant improvement in ODI was observed for the whole population, but there was no difference between groups $(0.6$; 95\% CI, -4.5 to $5.8 ; p=0.811)$. There were no differences between groups concerning EQ-5D $(-0.04 ; 95 \% \mathrm{CI},-0.15$ to $0.07 ; p=0.442)$, back pain NRS $(-0.4 ; 95 \% \mathrm{CI},-1.2$ to $0.4 ; p=0.279)$, leg pain NRS $(-0.4 ; 95 \% \mathrm{CI},-1.2$ to 0.5 ; $p=0.374)$ or perioperative complications $(1.0 \%$ for adolescents, $5.1 \%$ for adults, $p=0.072$ ).

Conclusions The effectiveness and safety of single-level microdiscectomy are similar in adolescents and the adult population at 1-year follow-up.

Keywords Adolescent · Disc herniation - Microdiscectomy · Spine

\section{Introduction}

The lumbosacral radicular syndrome, also known as sciatica, is commonly caused by a herniated disc [11]. In the majority of patients the natural course of sciatica is favourable [21]. The international consensus is that surgical treatment is offered if the radiating leg pain persists despite a period of conservative management [1]. In the adolescent population lumbar disc herniation (LDH) is rare, but when present it generally 
causes symptoms similar to those in the adult population [6]. In adults the outcome after surgical treatment of lumbar disc herniation with lumbar microdiscectomy is well established and favourable $[15,16,20]$, but treatment and outcome are less well defined in adolescents [6].

There seems to be different predisposing factors in the adolescent populations with LDH compared to the adult population. Dang et al. [5] reported recently that spinal malformations were more common in the adolescents, but outcome was not improved by fusion. Another factor causing LDH seen more often in adolescents is trauma [6] and, since adolescents have less widespread degeneration, the outcome may be better than in adults, as recently reported [12]. In adolescents the growing spine may also have an impact on outcome, and adolescents may have different demands and expectations with respect to outcome compared to their peers and compared to the adult population. Consequently, outcome studies with implementation of patient reported data in adolescent LDH patients are needed.

There are limited data on patient-reported outcomes after lumbar microdiscectomy in adolescents, and the literature consist largely of small, retrospective series [6]. To achieve adequate patient numbers to study rare entities and subgroups, such as adolescents, LDH spine registries are invaluable.

In fact, a recent study from the Swedish Spine Registry (SweSpine) demonstrated that adolescents were more satisfied and had fewer spine-related symptoms following surgery than adult patients [12]. The SweSpine study included patients that were operated on with both open discectomies and microdiscectomies $[12,19]$. As there is only one prospective study on surgical management of LDH in the adolescent population, there is a need to validate the results in another population to establish the effectiveness of treatment with high external validity [12]. As microdiscectomy is more common than open discectomies in the adolescent population, a more focused study is necessary to evaluate effectiveness of this particular procedure.

Due to the differences in aetiology and the sparse patient reported outcome data in the adolescent LDH population, further data are needed to assess treatment effectiveness in terms of patient reported outcomes and safety. We hypothesised that outcome in adolescents would be better compared to adults due to the more focal disease; thus, surgery, being a focal treatment, would be more targeted.

The primary aim of this registry-based study was to compare functional results at 1 year after single-level lumbar microdiscectomy in adolescents (13-19 years old) and younger adults (20-50 years old) with LDH using data from the Norwegian Registry for Spine Surgery (NORspine).

\section{Patients and methods}

\section{Study population}

Data for this observational study were collected through NORspine, a comprehensive registry for quality control and research. In total, 36 of 40 centres performing lumbar spine surgery in Norway report to NORspine. NORspine is linked to the National Registry and Statistics Norway, which contain information concerning everyone who either is or has been a resident in Norway. According to the Norwegian Directorate of Health, approximately $65 \%$ of all patients who undergo lumbar spine surgery in Norway are included in NORspine [13]. Participation in the registration by providers or patients was not mandatory, nor was participation required as a necessary condition for a patient to gain access to healthcare or for a provider to be eligible for payment. Follow-up time from the date of the operation was 1 year. Follow-up time from the date of the operation (baseline) was 1 year.

\section{Inclusion criteria}

1. Diagnosis of sciatica due to LDH

2. Scheduled operation (i.e. non-emergency surgery) with single-level lumbar microdiscectomy between January 2007 and May 2014

3. Included in the NORspine registry

4. Age at time of surgery between 13 and 50 years old

\section{Exclusion criteria}

1. History of lumbar spine surgery

2. Extraforaminal LDH

3. Spondylolisthesis and/or scoliosis

4. Fusion surgery

\section{Ethical approval}

The study was approved by the regional committee for medical research in Central-Norway (2016/840) and all participants provided written informed consent. The Norwegian Data Protection Authority approved the registry protocol.

\section{Primary outcome measure}

We used version 2.0 of the Oswestry Disability Index (ODI) [8] as the primary endpoint. ODI is a widely accepted outcome measure in surgery for degenerative lumbar spine disorders, including surgery for LDH $[2,22]$. This version is translated into Norwegian and has been validated for psychometric properties $[9,17]$. The ODI questionnaire is used to quantify 
disability for degenerative conditions of the lumbar spine and covers intensity of pain, ability to lift, ability to care for oneself, ability to walk, ability to sit, sexual function, ability to stand, social life, sleep quality and ability to travel. For each topic there are six statements describing potential scenarios, and patients select the one that most closely resembles their situation. The index is scored from 0 to 100 . Zero means no disability and 100 reflects maximum disability. The minimal important change (MIC) in ODI score is considered to be approximately 10 points [14].

\section{Secondary outcome measure}

Changes in generic health-related quality of life were measured with the generic EuroQol five dimensions (EQ-5D) instrument between baseline and 1-year follow-up. Intensity of pain was graded in two separate 0-10 numerical rating scales (NRSs) for back pain and leg pain, where 0 equals no pain and 10 represents the worst imaginable or ever experienced pain by the patient [10]. The NRS pain scales and ODI have shown good validity and are frequently used in research on back pain [9]. Complications were registered as described in the paragraph below. We also compared duration of procedures, length of hospital stays, and repeated surgery at the index level within 3 months of surgery between groups.

\section{Data collection and registration by the NORspine registry protocol}

On admission for surgery, the patients completed the baseline questionnaire, which included questions about demographics and lifestyle issues in addition to the primary and secondary outcome measure. Information about marital status, educational level, body-mass index (BMI) and tobacco smoking was available in the NORspine registry. During the hospital stay, using a standard registration form, the surgeon recorded data concerning diagnosis, previous lumbar spine surgery, comorbidity, American Society of Anesthesiologists (ASA) grade, treatment and image findings. The surgeons provided the following complications and adverse events to the NORspine registry: intraoperative haemorrhage requiring blood replacement, postoperative haematoma requiring repeated surgery, unintentional durotomy, nerve injury, cardiovascular complications, respiratory complications, anaphylactic reactions and wrong level surgery. Patients reported the following complications if they occurred within 3 months of surgery: wound infection, urinary tract infection, pneumonia, pulmonary embolism and deep vein thrombosis. A questionnaire was distributed to all patients at 3 months and 1 year after surgery. The patients who did not respond received one reminder with a new copy of the questionnaire. The patients completed preoperative questionnaire data and postal follow- up questionnaires without any assistance from the treating surgeon.

\section{Surgical procedures}

All patients underwent single-level lumbar microdiscectomy. Since this is a multicentre observational study, small variations in the surgical management may occur and the surgical procedures can only be described in general terms and in accordance with the data collected in the NORspine registry. The microsurgical discectomy involves preoperative fluoroscopy for detection of the target level, paramedian or median incision of about 3-6 cm, straight or curved opening of the paravertebral muscular fascia, subperiosteal release of the paravertebral musculature from the spinous process and basal lamina above and below the target disc-level. Self-retaining retractors (typically Caspar retractors) and a microscope or loupes are introduced. Often a flavectomy and arcotomy of the lamina above the disc-level are done. This is followed by careful mobilisation of the dural sac and the nerve-root medially, before evacuating the herniated disc. This might involve entering the disc space, or just removing a free sequestrated disc fragment (sequestrectomy).

\section{Statistical analysis}

Statistical analyses were performed with SPSS version 21 (IBM Corporation, Chicago, IL, USA). Statistical significance level was defined as $p \leq 0.05$ on the basis of a two-sided hypothesis test with no adjustments made for multiple comparisons. Central tendencies are presented as means when normally distributed and as medians when skewed. We used the chi-squared test for categorical variables. Baseline and 1-year scores were compared with paired-samples $t$-test. Mean change scores between the groups were analysed with independent-samples $t$-test. A multiple linear regression model was applied to assess the relationship between the difference in ODI score at 12-months (dependent variable) and age group (adolescence versus young adults), controlling for potential confounders. The multiple linear regression analysis included BMI (linear), adolescence (yes/no), sex, smoking (yes/no), and preoperative ODI (linear).

\section{Missing data}

For missing data we chose to exclude cases pairwise in the complete case analyses. This method excluded patients only if they were missing the data required for the specific analysis. They were still included in any of the analyses for which they had the necessary information. This strategy was based on a study on an equivalent patient population from NORspine that showed no difference in outcomes between responders and non-responders [18]. To minimise the number of missing data 
points, additional "last observation carried forward" analyses were also performed. In patients where the ODI score at 1 year after surgery was missing, we used the value registered at 3 months assuming little difference between these two time points.

\section{Results}

\section{Study population}

A total of 3,245 patients were enrolled out of 7,158 screened patients (Fig. 1). Among the 7,158 patients screened for inclusion, 752 underwent open discectomy and were excluded from the study. There were 97 adolescents and 3,148 adults. The mean age at baseline was $37.0( \pm 8.3)$ years and $40.7 \%$ were females. Baseline characteristics are presented in Table 1.

\section{Oswestry Disability Index}

Complete 1-year follow-up for ODI was achieved in $63.8 \%$ of patients $(n=2,071)$ with no differences between adolescents and adult patients $(59.8 \%$ vs $63.9 \%, p=0.402)$. For the whole study population there was an improvement of 27.2 points in ODI at 1 year $(95 \%$ CI, $26.3-28.0 ; p<0.001)$. In a complete case analysis $(n=2,071)$ there was no difference in mean ODI change between age cohorts at 1-year follow-up (mean difference, $0.6 ; 95 \% \mathrm{CI},-4.5$ to $5.8 ; p=0.811$ ). Among the 2071 patients with complete 1 -year follow-up, $82.7 \%(n=1,711)$ achieved a MIC predefined as an improvement of $\geq 10$ points in ODI score from baseline. At 1 year, $86.2 \%$ of adolescents had achieved a MIC, compared to $82.6 \%$ of adult patients $(p=0.474)$. Changes in ODI score are presented in Table 2.

\section{Secondary outcomes}

Changes in EQ-5D, back pain NRS and leg pain NRS after 1year follow-up for both age groups are presented in Table 2. No differences between the two age groups were found for any of the secondary patient-reported outcomes. Details regarding surgical treatment, duration of procedure, hospitalisation period and complications are presented in Table 3. There were no differences between groups in duration of surgery. Adolescents had slightly longer hospital stays (mean difference, 0.4 days; $p<0.042$ ). Further, there were no differences in the rate of repeated surgery for any cause within 3 months between adolescents and adults ( $0 \%$ vs $1.2 \%$, $p=0.270)$. The proportion of patients experiencing one or more complications within 3 months of surgery (both surgeon and patient-reported) was $5.0 \%(n=160)$. There were no differences between groups in perioperative complications
Fig. 1 Study enrollment and follow-up

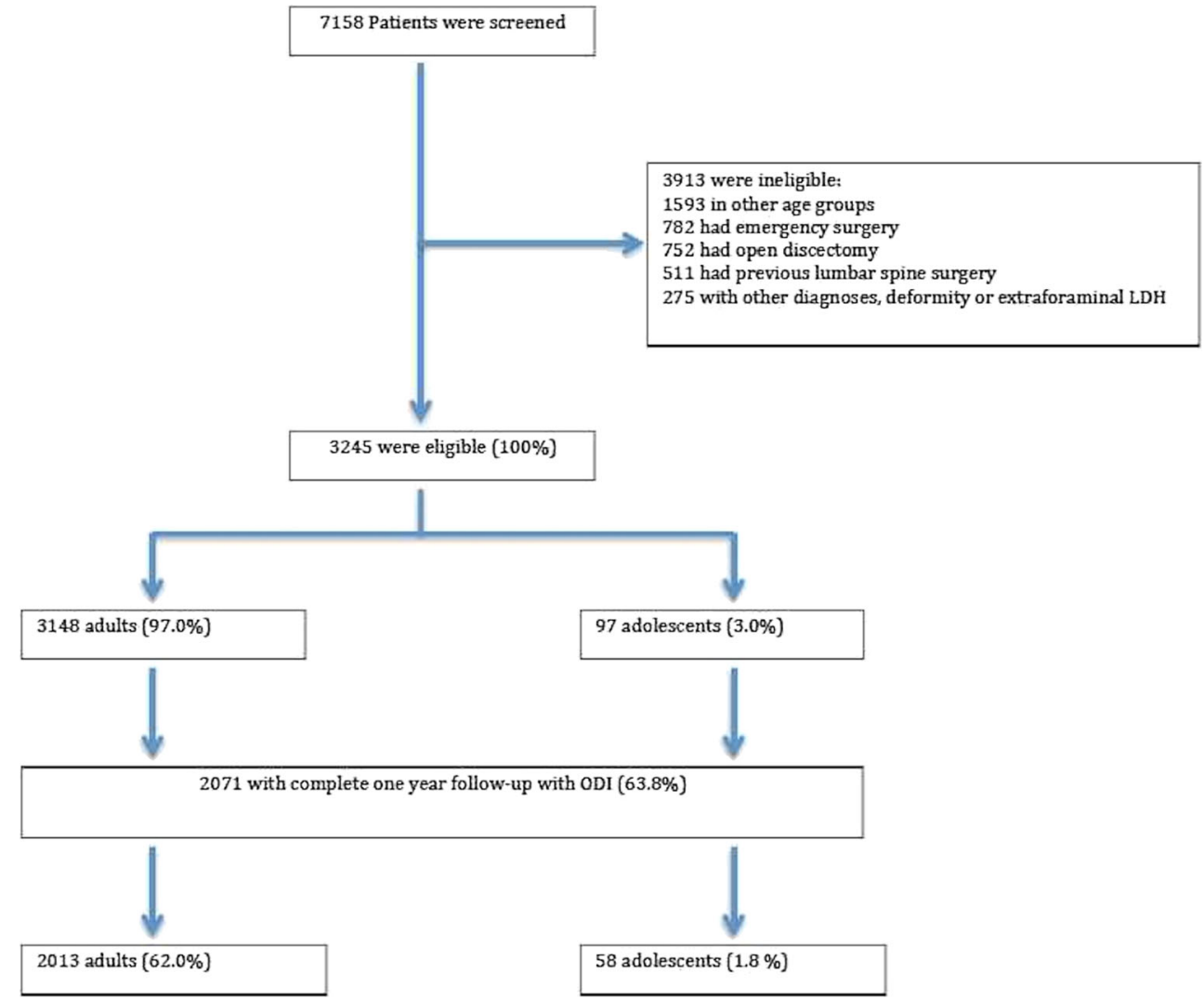


Table 1 Demographic characteristics, coexisting illnesses and measures of health status for both groups $(n=3,245)$

\begin{tabular}{|c|c|c|c|}
\hline Variable & $\begin{array}{l}\text { Adolescents (age <20), } \\
n=97\end{array}$ & $\begin{array}{l}\text { Adults (age 20-50), } \\
n=3,148\end{array}$ & $p$ value \\
\hline Mean age, years $\pm S D$ & $17.5 \pm 1.6$ & $37.6 \pm 7.7$ & $<0.001$ \\
\hline Female sex, no. $(\%)$ & $48(49.5)$ & $1271(40.4)$ & 0.072 \\
\hline $\mathrm{BMI} \pm \mathrm{SD}^{\mathrm{a}}$ & $24.4 \pm 4.1$ & $26.5 \pm 4.4$ & $<0.001$ \\
\hline Daily tobacco smoking, no. (\%) & $13(13.4)$ & $955(30.7)$ & $<0.001$ \\
\hline ASA grade $>2^{\mathrm{b}}$ & $0(0)$ & $47(1.5)$ & 0.224 \\
\hline Preoperative ODI $\pm \mathrm{SD}^{\mathrm{c}}$ & $33.9 \pm 13.0$ & $41.3 \pm 16.6$ & $<0.001$ \\
\hline Preoperative EQ-5D $\pm \mathrm{SD}$ & $0.38 \pm 0.34$ & $0.34 \pm 0.34$ & 0.265 \\
\hline Preoperative leg pain (NRS) \pm SD & $6.3 \pm 2.2$ & $6.5 \pm 2.2$ & 0.525 \\
\hline Preoperative back pain $(\mathrm{NRS}) \pm \mathrm{SD}$ & $5.6 \pm 2.5$ & $5.8 \pm 2.3$ & 0.333 \\
\hline Preoperative paresis, no. $(\%)$ & $2(2.1)$ & $342(10.9)$ & 0.006 \\
\hline Duration of leg pain >1 year, no. (\%) & $28(29.5)$ & $720(24.0)$ & 0.221 \\
\hline
\end{tabular}

${ }^{\mathrm{a}}$ The bodymass index $(B M I)$ is the weight in kilograms divided by the square of the height in metres

${ }^{\mathrm{b}}$ The American Society of Anesthesiologists (ASA) grade ranges from I to V; grade V is the worst, indicating lifethreating condition

${ }^{\mathrm{c}}$ Oswestry Disability Index $(O D I)$ ranges from 0 to 100 ; lower scores indicating less severe symptoms (i.e. during hospital admission) or complications occurring within 3 months of surgery.

\section{Multiple regression analysis}

A multiple regression analysis was performed with difference in ODI score at 1 year as the dependent variable (Table 4). Smoking $(p<0.001)$, ASA grade $>2(p=0.003)$, female sex $(p=0.010)$, BMI $(p=0.011)$ and preoperative ODI $(p<0.001)$ were associated with statistically significant ODI change at 1 year, whereas no association was found for adolescence $(p=0.103)$.

\section{Discussion}

This multicentre observational study from NORspine shows similar effectiveness and safety of single-level lumbar microdiscectomy in adolescents and adults at 1 year. A MIC was achieved in $86 \%$ of adolescents following microdiscectomy for LDH, similar to the adult population.
Clinical outcomes after surgical treatment for LDH in the adolescent population are mostly limited to retrospective case series [6]. Our findings support the retrospective findings that this is an effective procedure, although as expected in a prospective study using patient reported outcomes, the success rates are somewhat lower than in the retrospective case series with surgeon reported outcomes [6]. In a recent observational study from SweSpine, Lagerbäck et al. [12] found that adolescents were more satisfied and had fewer spine related symptoms following surgery than adult patients. The primary outcome variable in the Swedish study was a crude self-rating of satisfaction of surgical outcomes. Our study shows that the improvements in ODI and EQ-5D at 1 year were similar in adolescents compared to the adult group. The study by Lagerbäck et al. was larger with 151 adolescent patients, but did not provide details about the surgical procedure. In a related study from SweSpine in the same time period there were $49 \%$ open discectomies [19]. However, we think that there are no reasons why spine surgeons should choose open procedures in adolescent patients if microdiscectomy offers similar improvement. Our series with 97 adolescent patients

Table 2 Primary and secondary patient reported outcomes at 1 year

\begin{tabular}{|c|c|c|c|c|c|c|c|c|}
\hline \multicolumn{9}{|c|}{ Complete case analysis } \\
\hline & \multicolumn{3}{|c|}{ Adolescents $(n=59)$} & \multicolumn{3}{|c|}{ Adults $(n=2,013)$} & \multirow[t]{2}{*}{ Difference in mean change between groups $(95 \% \mathrm{CI})$} & \multirow[t]{2}{*}{$p$ value } \\
\hline & Baseline & 1 year & Mean change & Baseline & 1 year & Mean change & & \\
\hline ODI & 35.0 & 8.5 & 26.5 & 41.3 & 14.1 & 27.2 & $0.6(-4.5,5.8)$ & 0.811 \\
\hline EQ-5D & 0.36 & 0.83 & 0.48 & 0.34 & 0.78 & 0.43 & $-0.04(-0.15,0.07)$ & 0.442 \\
\hline Back pain NRS & 5.7 & 2.2 & 3.5 & 5.7 & 2.7 & 3.1 & $-0.4(-1.2,0.4)$ & 0.279 \\
\hline Leg pain NRS & 6.3 & 1.4 & 4.9 & 6.5 & 2.0 & 4.5 & $-0.4(-1.2,0.5)$ & 0.374 \\
\hline \multicolumn{9}{|c|}{ Last value carried forward analysis } \\
\hline & \multicolumn{3}{|c|}{ Adolescents $(n=77)$} & \multicolumn{3}{|c|}{ Adults $(n=2,470)$} & Difference in mean change between groups $(95 \% \mathrm{CI})$ & $P$-value \\
\hline & Baseline & 1 year & Mean change & Baseline & 1 year & Mean change & & \\
\hline ODI & 33.7 & 8.3 & 25.4 & 41.2 & 14.6 & 26.6 & $1.2(-3.3,5.8)$ & 0.593 \\
\hline EQ-5D & 0.38 & 0.85 & 0.47 & 0.34 & 0.77 & 0.43 & $-0.04(-0.13,0.05)$ & 0.386 \\
\hline Back pain NRS & 5.5 & 2.0 & 3.5 & 5.8 & 2.7 & 3.1 & $-0.4(-1.1,0.3)$ & 0.261 \\
\hline Leg pain NRS & 6.4 & 1.3 & 5.0 & 6.5 & 2.0 & 4.5 & $-0.5(-1.2,0.2)$ & 0.173 \\
\hline
\end{tabular}


Table 3 Surgical treatments, complications and events

\begin{tabular}{llll}
\hline Variable & $\begin{array}{l}\text { Adolescents } \\
(n=97)\end{array}$ & $\begin{array}{l}\text { Adults, 20-50 } \\
\text { years }(n=3,148)\end{array}$ & $p$ value \\
\hline Level operated, no. (\%) & & & \\
- L2/L3 & $1(1.0)$ & $18(0.6 \%)$ & 0.559 \\
- L3/L4 & $2(2.1)$ & $83(2.6)$ & 0.727 \\
- L4/L5 & $55(56.7)$ & $1,235(39.2)$ & 0.001 \\
- L5/S1 & $39(40.2)$ & $1,812(57.6)$ & 0.001 \\
Operation time (minutes) & 56.6 & 54.7 & 0.488 \\
Days in hospital, no. & 1.9 & 1.5 & 0.042 \\
Any complication, no. (\%) & $1(1.0)$ & $159(5.1)$ & 0.072 \\
Perioperative complications, no. (\%) & $0(0.0)$ & $63(2.0)$ & 0.159 \\
- Dural tear or spinal fluid leak & $0(0)$ & $35(1.1)$ & 0.296 \\
- Nerve injury & $0(0)$ & $6(0.2)$ & 0.667 \\
- Blood replacement or postoperative haematoma & $0(0)$ & $11(0.3)$ & 0.560 \\
- Cardiovascular complications & $0(0)$ & $1(0.0)$ & 0.861 \\
- Respiratory complications & $0(0)$ & $1(0.0)$ & 0.861 \\
- Anaphylactic reaction & $0(0)$ & $4(0.1)$ & 0.725 \\
- Wrong level surgery & $0(0)$ & $4(0.1)$ & 0.725 \\
Complications within 3 months, no. (\%) & $1(1.5)$ & $100(4.9)$ & 0.214 \\
- Wound infection & $0(0)$ & $57(2.8)$ & 0.173 \\
- Urinary tract infection & $0(0)$ & $20(1.0)$ & 0.424 \\
- Pneumonia & $0(0)$ & $7(0.3)$ & 0.637 \\
- Pulmonary embolism & $0(0)$ & $0(0)$ & - \\
- Deep vein thrombosis & $0(0)$ & $0(0)$ & 0.787 \\
- Micturition problems & $1(1.5)$ & $24(1.2)$ & \\
\hline
\end{tabular}

undergoing microdiscectomy is the largest prospective study to date evaluating results after minimally invasive spine surgery in this age group. Based on these two registry-based studies, it is not possible to directly compare open discectomy with microdiscectomy; however, it is interesting that the $86 \%$ satisfaction rate reported by Lagerbäck et al. compares well to the $86 \%$ of our patients achieving the MIC for ODI.

Our study seems to be consistent with previous studies showing that adolescents have less severe symptoms at baseline and that adolescents are less likely to present with paresis $[6,12]$. The same trend was observed in the recent SweSpine study; however, in their study EQ-5D scores were higher (i.e. experiencing less problems) among adolescents. This is not unexpected since NRS captures pain intensity only, while the
ODI and EQ-5D are multi-dimensional and focus on functional status. A clinical relevant age effect per se in EQ-5D is not expected, but spine-related or other co-morbidity may influence results [3]. Moreover, adolescents are expected to have less spinal degenerative changes at presentation.

Finally, based on the literature, it seems that surgical treatment of LDH in the adolescent population is a safe procedure with low operative complications, although open discectomies seem to be the dominating procedure $[4,12]$. Our study demonstrates safety also after lumbar microdiscectomy with a complication rate of only $1 \%$. The low complication rate in our study might be related to the young age of included patients and exclusion of individuals who had undergone previous lumbar spine surgery.
Table 4 Multiple regression analysis with change in ODI at 1 year as the dependent variable

\begin{tabular}{llll}
\hline Variable & Parameter estimate & $95 \%$ confidence interval & $p$ value \\
\hline Adolescent & 3.4 & $-4.5,4.6$ & 0.103 \\
Oswestry score, pre-surgery & 0.9 & $0.8,0.9$ & $<0.001$ \\
Smoking & -5.7 & $-7.2,-4.3$ & $<0.001$ \\
ASA grade $>2$ & -8.7 & $-14.5,-2.9$ & 0.003 \\
Female sex & -1.8 & $-3.1,-0.4$ & 0.010 \\
BMI & -0.2 & $-0.4,-0.05$ & 0.011 \\
\hline
\end{tabular}

A negative score means a worsening of ODI score 1 year after surgery 


\section{Study strengths and limitations}

The results in the present study were strengthened by the use of specific inclusion and exclusion criteria, prospective data collection and the large sample size. One of the main advantages of using data from spine registries such as NORspine is the use of widely accepted and validated outcome measures such as ODI, EQ-5D, back pain NRS and leg pain NRS. The preoperative baseline values of our outcome measures reflect indications for surgery. Further, the use of prospectively collected outcomes make future comparisons across clinical studies much more feasible. Moreover, patient-reported outcomes in neurosurgical research are often lacking and may provide a better understanding of the effectiveness and safety of surgical procedures [7]. The main limitation of the present study is that the loss to follow-up was relatively high. However, in a study on an equivalent patient population with $22 \%$ non-responders, no difference in outcomes between responders and nonresponders was found at long-term follow-up [18].

Also, ideally we would have a control group undergoing conservative management. However, based on the symptom duration, it is unlikely that adolescents are fast-tracked to surgery, and faster recovery and surgical treatment is reserved for acute or intolerable pain, or when conservative treatment fails. Similar to SweSpine, the NORspine registry covers degenerative spine surgery as a whole and consequently no validated adolescent outcome measures were used [12]. Although we found no difference at 1 year, a longer follow-up may be warranted to investigate surgery rates for disc reherniation and detect progression of symptoms and back-pain-related disability.

\section{Conclusions}

At 1 year, the effectiveness and safety of one level microdiscectomy are similar in adolescents and the adult population.

Acknowledgements The authors would like to thank the Norwegian Registry for Spine Surgery (NORspine). The NORspine registry receives funding from the University of Northern Norway and Norwegian health authorities. We thank all patients and surgeons participating in NORspine registration.

Authors' contributions All authors read and approved the final manuscript. S.G.: study design, collection of data, statistics and writing; A.S.J.: study design and drafting of the manuscript; M.A.M. and C.H.: statistics and writing; A.S., Ø.P.N. and T.K.S.: collection of data and writing.

\section{Compliance with ethical standards}

Conflicts of interest All authors certify that they have no affiliations with or involvement in any organisation or entity with any financial interest (such as honoraria; educational grants; participation in speakers' bureaus; membership, employment, consultancies, stock ownership, or other equity interest; and expert testimony or patent-licensing arrangements), or non-financial interest (such as personal or professional relationships, affiliations, knowledge or beliefs) in the subject matter or materials discussed in this manuscript.

Funding No funding was received for this research.

Ethical approval All procedures performed in studies involving human participants were in accordance with the ethical standards of the institutional and/or national research committee and with the 1964 Helsinki declaration and its later amendments or comparable ethical standards

Informed consent Informed consent was obtained from all individual participants included in the study.

Open Access This article is distributed under the terms of the Creative Commons Attribution 4.0 International License (http:// creativecommons.org/licenses/by/4.0/), which permits unrestricted use, distribution, and reproduction in any medium, provided you give appropriate credit to the original author(s) and the source, provide a link to the Creative Commons license, and indicate if changes were made.

\section{References}

1. Andersson GB, Brown MD, Dvorak J, Herzog RJ, Kambin P, Malter A, McCulloch JA, Saal JA, Spratt KF, Weinstein JN (1996) Consensus summary of the diagnosis and treatment of lumbar disc herniation. Spine 21:75S-78S

2. Arden NK, Price C, Reading I, Stubbing J, Hazelgrove J, Dunne C, Michel M, Rogers P, Cooper C (2005) A multicentre randomized controlled trial of epidural corticosteroid injections for sciatica: the WEST study. Rheumatology (Oxford) 44:1399-1406

3. Burstrom K, Johannesson M, Diderichsen F (2001) Swedish population health-related quality of life results using the EQ-5D. Qual Life Res 10:621-635

4. Cahill KS, Dunn I, Gunnarsson T, Proctor MR (2010) Lumbar microdiscectomy in pediatric patients: a large single-institution series. J Neurosurg Spine 12:165-170

5. Dang L, Chen Z, Liu X, Guo Z, Qi Q, Li W, Zeng Y, Jiang L, Wei F, Sun C, Liu Z (2015) Lumbar disk herniation in children and adolescents: the significance of configurations of the lumbar spine. Neurosurgery 77:954-959, discussion 959

6. Dang L, Liu Z (2010) A review of current treatment for lumbar disc herniation in children and adolescents. Eur Spine J 19:205-214

7. Drewes C, Sagberg LM, Jakola AS, Gulati S, Solheim O (2015) Morbidity after intracranial tumor surgery: sensitivity and specificity of retrospective review of medical records compared with patient-reported outcomes at 30 days. J Neurosurg 123:972-977

8. Fairbank JC, Couper J, Davies JB, O'Brien JP (1980) The Oswestry low back pain disability questionnaire. Physiotherapy 66:271-273

9. Grotle M, Brox JI, Vollestad NK (2003) Cross-cultural adaptation of the Norwegian versions of the Roland-Morris disability questionnaire and the Oswestry disability index. J Rehabil Med 35: 241-247

10. Jensen MP, Karoly P (1992) Self-report scales and procedures for assessing pain in adults. In: Truk DC, Melzack R (eds) Handbook of pain assessment. Guilford Press, New York, pp 135-151 
11. Koes BW, van Tulder MW, Peul WC (2007) Diagnosis and treatment of sciatica. BMJ 334:1313-1317

12. Lagerback T, Elkan P, Moller H, Grauers A, Diarbakerli E, Gerdhem P (2015) An observational study on the outcome after surgery for lumbar disc herniation in adolescents compared with adults based on the Swedish Spine Register. Spine J 15:1241-1247

13. Nerland US, Jakola AS, Solheim O, Weber C, Rao V, Lonne G, Solberg TK, Salvesen O, Carlsen SM, Nygaard OP, Gulati S (2015) Minimally invasive decompression versus open laminectomy for central stenosis of the lumbar spine: pragmatic comparative effectiveness study. BMJ 350:h1603

14. Ostelo RW, Deyo RA, Stratford P, Waddell G, Croft P, Von Korff M, Bouter LM, de Vet HC (2008) Interpreting change scores for pain and functional status in low back pain: towards international consensus regarding minimal important change. Spine 33:90-94

15. Peul WC, van den Hout WB, Brand R, Thomeer RT, Koes BW (2008) Prolonged conservative care versus early surgery in patients with sciatica caused by lumbar disc herniation: two year results of a randomised controlled trial. BMJ 336:1355-1358

16. Peul WC, van Houwelingen HC, van den Hout WB, Brand R, Eekhof JA, Tans JT, Thomeer RT, Koes BW (2007) Surgery versus prolonged conservative treatment for sciatica. N Engl J Med 356: $2245-2256$
17. Solberg TK, Olsen JA, Ingebrigtsen T, Hofoss D, Nygaard OP (2005) Health-related quality of life assessment by the EuroQol5D can provide cost-utility data in the field of low-back surgery. Eur Spine J 14:1000-1007

18. Solberg TK, Sorlie A, Sjaavik K, Nygaard OP, Ingebrigtsen T (2011) Would loss to follow-up bias the outcome evaluation of patients operated for degenerative disorders of the lumbar spine? Acta Orthop 82:56-63

19. Stromqvist F, Stromqvist B, Jonsson B, Gerdhem P, Karlsson MK (2016) Lumbar disc herniation surgery in children: outcome and gender differences. Eur Spine J 25:657-663

20. van den Hout WB, Peul WC, Koes BW, Brand R, Kievit J, Thomeer RT (2008) Prolonged conservative care versus early surgery in patients with sciatica from lumbar disc herniation: cost utility analysis alongside a randomised controlled trial. BMJ 336: $1351-1354$

21. Vroomen PC, de Krom MC, Wilmink JT, Kester AD, Knottnerus JA (1999) Lack of effectiveness of bed rest for sciatica. N Engl J Med 340:418-423

22. Weinstein JN, Lurie JD, Tosteson TD, Skinner JS, Hanscom B, Tosteson AN, Herkowitz H, Fischgrund J, Cammisa FP, Albert T, Deyo RA (2006) Surgical vs nonoperative treatment for lumbar disk herniation: the Spine Patient Outcomes Research Trial (SPORT) observational cohort. JAMA 296:2451-2459 